\title{
Pregnant women with fetal abnormalities: the forgotten people in the abortion debate
}

\author{
Lachlan J de Crespigny and Julian Savulescu
}

$\mathrm{D}$ ebate on abortion law reform focuses on early abortion, but it is couples with planned pregnancies undergoing prenatal testing who suffer most because of Australia's unclear and outdated abortion laws. In 30 years of obstetric ultrasound practice, one of us ( $\mathrm{LJ} \mathrm{d} \mathrm{C}$ ) has seen how the diagnosis of a fetal abnormality affects couples hoping to raise a family - it is their worst nightmare. Compounding this, as many discover, are uncertain laws and obstetricians' fears regarding later abortion that result in delays and further heartache.

Women are being denied timely prenatal testing and abortion for fetal abnormality, even when the abnormality is so severe that if the baby were born, the parents would be given the option of nontreatment.

In July 2007, it was announced that a private member's bill would be introduced into Victorian Parliament to decriminalise abortion. Curiously, the proposed reforms do not address the overlapping law relating to "child destruction". The state government asked the Victorian Law Reform Commission to develop legislative options for decriminalisation of abortion.

Here, we discuss these issues from a Victorian perspective, but they are applicable nationally.

\section{The law}

Australian abortion laws vary throughout jurisdictions and are summarised elsewhere. ${ }^{1,2}$ Nearly all include a "maternal interests" criterion for abortion. ${ }^{1}$ This is the sole criterion in Victoria, New South Wales, Queensland and Tasmania, where even a "lethal" fetal abnormality is not legal grounds for abortion. The only Australian jurisdiction to have removed abortion from its criminal statutes is the Australian Capital Territory.

In Victoria, the 1969 Menhennitt ruling ${ }^{3}$ on what is considered an "unlawful" abortion under the Crimes Act 1958 (Vic) does not specify a gestation limit, and the law is liberally interpreted to apply until around 12 weeks' gestation. Abortion can be difficult to access after 12 weeks, even though the same law still applies. The separate crime of child destruction (eg, Crimes Act, s. 10) adds to legal uncertainty - this crime applies later in pregnancy (except in NSW, where the law does not include the crime of child destruction). In Victoria, it now probably applies from 24 weeks or even earlier. The situations and gestations when the laws for both

Kate had fetal borderline cerebral ventriculomegaly demonstrated at 19 weeks' gestation. A second opinion at 21 weeks suspected agenesis of the corpus callosum. Amniocentesis was performed, and Kate consulted with a geneticist. Fetal magnetic resonance imaging was recommended. The outlook of this abnormality is variable, but can be extremely poor.

Kate requested termination of the pregnancy. She was referred to another public hospital (she had been booked at a Catholic hospital) that commenced a round of repeat consultations and investigations. The case was referred to the hospital's anonymous termination committee, which approved abortion at 24 weeks.

\section{ABSTRACT}

- Abortion law reform focuses on early abortion. Women wanting to have a family who have a fetal abnormality detected later in pregnancy are neglected in the debate and harmed by the consequences of current legal uncertainty.

- Unclear abortion laws compromise: the quality of prenatal testing; management when an abnormality is found; and patient care, through obstetricians' fears of legal repercussions.

- Women carrying a fetus with an abnormality are being denied abortion, even when the abnormality is so severe that nontreatment would be an option if the baby were born.

- Many women are likely to refuse to consider motherhood if they are denied appropriate prenatal testing and access to abortion if serious abnormalities are detected.

- Current abortion laws result in discriminatory and inconsistent practices, where access to prenatal testing and termination of pregnancy depends on location, the values of the treating doctor or hospital ethics committee, and a woman's personal resources.

- Legal certainty is needed to reduce the suffering of couples wanting to have a family.

MJA 2008; 188: 100-103

abortion and child destruction apply are variable and uncertain. Hence, two differing laws can apply in any particular case.

Doctors generally perceive that they run minimal risk of unlawful abortion charges before 12 weeks' gestation, but that the risk increases after 12 weeks, and particularly after 20 weeks.

\section{Prenatal tests}

Routine tests are available for two kinds of fetal abnormality:

- Chromosomal - more than 80\% of Victorian women are tested, primarily for Down syndrome; and

- Structural - virtually all women have a mid-trimester ultrasound scan, usually at 19 or 20 weeks. It is often better done later (eg, in overweight women or to review uncertain findings). Accuracy of ultrasound testing is enhanced if scans are routinely performed at 22-24 weeks. This is possible in the United Kingdom, where there are clear abortion laws, but where access to abortion is limited from 20 weeks (or earlier), as is the case in Australia, accuracy of prenatal testing for many women is compromised.

Hence, abortions after fetal abnormality is diagnosed on ultrasound typically take place around 20 weeks, or later.

Access to prenatal testing "allows" women to have children. Women at risk of passing on a genetic condition may perceive prenatal testing as providing the means to have a much wanted healthy child. Less than $2 \%$ of abortions occur after an abnormal prenatal test result; ${ }^{4}$ but without reliable testing — and the option 
of abortion if a fetal abnormality is found — many women might refuse to consider motherhood. ${ }^{5-7}$

Most women will request abortion after the diagnosis of a major fetal abnormality - 95\% do so after the diagnosis of Down syndrome in Victoria (J Halliday, Head, Public Health Genetics, Murdoch Childrens Research Institute, Melbourne, personal communication). When a major fetal abnormality is diagnosed, clinical experience shows that even women who consider themselves to be antichoice commonly reevaluate their in-principle opposition to abortion.

Fiona was almost 20 weeks' pregnant when doctors discovered inoperable fetal heart tumours. The fetus would die, either before or shortly after birth, and Fiona and her husband felt it would be too cruel to proceed. She was referred for abortion at 21 weeks.

The hospital refused to perform the procedure, instead referring her case to its committee and repeating tests. After almost 2 weeks without a date set for the termination, Fiona was secretly given details of a private abortion clinic by a hospital staff member. She had the procedure done at 24 weeks, costing her about $\$ 4000$. Fiona, who suffers from depression, said the ordeal caused her to have a nervous breakdown. "It's still very much taboo, even at [the women's] hospital. It's treated like it's something shameful", she said. "They are so scared of these politicians." 8

\section{Access to later abortion in Victoria}

Women who request a later abortion after the shocking news of a major fetal abnormality may face a harrowing journey and feel that they have been abandoned by hospitals and doctors. The diagnosis and a woman's reluctant request for abortion are distressing enough, but if she attends a private obstetrician, there is a high likelihood that the doctor will not run the personal risk of performing the abortion. If she attends a Catholic hospital, she must go elsewhere. Few rural hospitals offer abortion - women usually must travel to the city.

A woman can attend one of the few city public hospitals that offer later abortion, but this requires reassessment, more counselling and, typically, submitting herself for scrutiny. Only if her reasons are accepted will she be granted an abortion. She may, after weeks of delay, be refused. Such refusals may leave women embittered, not just because of the devastating outcome to their much wanted pregnancy, but because of the impersonal and arbitrary system they had to navigate. Women are reluctant to complain, as it would necessitate both reliving the anguish of the diagnosis and subsequent decision making, and being judged by others for requesting later termination on the grounds of disability in their child.

Committees, usually anonymous, that have been established in hospitals can be yet another hurdle for these women. The committee may decide whether a woman can have an abortion without meeting her - the expertise that committee members have in making such weighty decisions about a woman's life is often unclear, as is their expertise in ethics. Abortion is one of the few medical interventions in which the doctor-patient relationship is regularly overridden by uninvolved third parties with dubious moral authority. Committee members may have clinical, nursing or other expertise; these committees are often not legally qualified to interpret the law.

It can be argued that when lawful abortion is refused, there has been a breach of duty of care. If patients were so inclined, they could sue the individuals involved.

\section{Obstetricians' personal fears}

In late 2006, one of us (LJ d C) conducted a survey of Melbourne obstetricians, to see whether it has become harder for Victorian private patients to get a lawful abortion after a diagnosis of fetal abnormality and, if so, why. The survey findings highlight the concerns of doctors who are at the cutting edge of managing difficult clinical problems.

Participants were central Melbourne obstetricians who had no religious or conscientious objection to offering abortion for serious fetal abnormality. The survey was sent to 26 obstetricians selected because they specialised in treating women with abnormal pregnancies. Responses were received from 20 (77\%; nine female, 11 male). Ethics committee approval was not sought for this study, as it was judged to be an audit of practice and the anonymity of the survey enabled its completion to constitute consent.

Only one of the 20 responding obstetricians believed that Victoria's abortion laws are clear and appropriate. Of the other 19, unclear laws worried 15 personally, and affected patient management for 12 . Seventeen of 18 respondents said that their uncertainty included unclear child destruction laws. Worryingly, all respondents who thought that the laws were unclear believed that this affected the patient management of other practitioners, thereby limiting access to lawful abortion. Fourteen obstetricians said that they had recently limited their offering of abortion for fetal abnormality; reasons for this included press coverage (nine obstetricians), the Royal Women's Hospital (RWH) late abortion case (11), ${ }^{*}$ and increased concern about legal uncertainty (12).

Comments from obstetricians about access to lawful abortion included: "Too difficult. Too restrictive. Too much at whim of abortion committee" and "Fine before 14 weeks, poor from 14 to 24 weeks, almost absent after 24 weeks".

Although this study was limited to a small number of Melbourne obstetricians, these doctors see a disproportionate number of abnormal pregnancies, and have particular insight into the cost of restrictive abortion laws. Many such women are referred to them by doctors who are unwilling — without legal clarity — to offer the full range of prenatal care. However, since Victoria has the only free-standing clinic offering late abortion in Australia, the state acts as a de facto referral centre for late terminations: in 2005, 104 of the 180 post-20-week terminations when there was no fetal anomaly were for women from interstate or overseas. ${ }^{10}$ This is indirect evidence that fear and unclear laws also exist in other states, that effectively export these women for care.

Uncertain laws compromise good prenatal care, at least for Victorian women, because medical uncertainty about the law leads to:

- Abortion being denied;

- Ultrasound scans often being performed too early, leading to incomplete or possibly inaccurate prenatal diagnoses being provided to women as their basis for decision making; and

- Women opting for earlier termination on the basis of uncertain fetal diagnostic results, when the option of later termination would allow them to wait and see what happens, and potentially - if the problem resolves - carry the pregnancy through.

\footnotetext{
* The late abortion case at the RWH in Melbourne in 2000 was widely publicised. 1,9 A woman requesting pregnancy termination was referred at 31 weeks' gestation; her fetus had been diagnosed with skeletal dysplasia, most likely achondroplasia. Termination was performed at 32 weeks on the grounds that the woman was acutely suicidal. $L J d C$ was one of the treating doctors.
} 
Former President of the Australian Medical Association (AMA), Dr Mukesh Haikerwal, said that: "The AMA is concerned that a situation could arise where doctors could be compromising patient care for fear of legal repercussions". ${ }^{11}$ This already happens, at least in Victoria.

As obstetricians in the survey commented:

Overall change is to "dilute the responsibility"... ie, even with gross abnormalities with private patients, I involve ethics committees, second opinions, etc. This leads to delays and more trauma to the patient. It can move the gestation to over 20 weeks.

Most obstetric care providers (I think) are caught in the dilemma of wishing such safe and accessible services to be provided, but not by them

There is a looming manpower crisis in the provision of obstetric services. ${ }^{12}$ Potential trainees could be further discouraged from entering obstetrics if they were aware that to provide ethical, lawful treatment to their patients, they must risk their own careers and wellbeing. The staff who managed the 32 -week late abortion case at the RWH, including LJ d C, were subjected to multiple investigations over 6 years, with no fault found. However, this caused them intense personal and family disruption; all resigned from the hospital, some to change career paths and reduce clinical practice. This is not a happy career trajectory for young doctors.

Good clinical care often takes a back seat to risk minimisation for providers, as Mary discovered. ${ }^{13}$ At 20 weeks' gestation, she decided that she could not continue with her high-risk pregnancy. She was told that abortion was refused by the hospital, not because it was illegal but because the hospital was concerned about the current "political climate"; the emotive debate over later abortions was behind a decision to deny her the lawful procedure.

She had the abortion done privately, costing her hundreds of dollars. "I'm concerned this could happen to other women and that some wouldn't have the financial means, support or resourcefulness to go elsewhere", she said.

\section{Catholic hospitals}

Personal experience (LJd C) shows that women booking to give birth at Catholic hospitals are not usually informed at the outset that if they have a major abnormality diagnosed, the hospital will not offer abortion. They can attempt to move to another hospital after such a diagnosis, but other hospitals may be reluctant, or refuse, to offer care. The second hospital may have trouble offering services to these women, especially as many obstetric hospitals are Catholic (eg, one in three of Melbourne's major teaching hospitals). A similar problem exists in the United States, where many physicians do not consider themselves obligated to disclose relevant information or refer patients for legal but morally controversial medical procedures. ${ }^{14}$

\section{Perinatal care at the borderlines of viability}

There is an unreasonable contrast between obstetric and neonatal management after 20 weeks' gestation. Paediatricians recommend that the parents of a normal infant born at 24-26 weeks should decide whether or not their baby is treated, ${ }^{15,16}$ even if there is some chance of survival. Yet at the same gestation, with the same prognosis, late abortion is likely to be refused. Paediatricians will also discuss with the family the option of withdrawing intensive care in some cases where an older baby is severely affected with
Bernadette requested chorionic villus sampling after a thickened nuchal translucency was seen at 12 weeks, indicating an increased risk of chromosomal abnormality. The fetus was found to have Down syndrome, and she requested an abortion. This was not available because she was booked at a Catholic hospital. Her doctor agreed to refer her to a non-Catholic hospital. She reluctantly agreed - she did not want to move to a new hospital and new doctors at this distressing time.

The hospital was too busy to see her. After several telephone calls, she was fortunate that a private provider agreed to see her. She had an abortion, which cost her \$1200; money she could ill afford.

abnormalities but is still capable of surviving. It seems the fetus inside a woman's body has a higher moral status than a newborn infant of the same gestation outside the woman's body.

The uterus is indeed the best intensive care unit; fetuses with the most terrible abnormalities usually do not die before birth. Denying abortion may only delay the inevitable and extend the suffering of the family.

Many people see the borderline of potential fetal viability - the time from when the baby could survive if born alive - as a critical moment in the abortion debate. However, women who request abortion "late" in pregnancy commonly have a fetus with an abnormality that makes it less likely to survive preterm birth (eg, with a hypoplastic left heart, there may be little chance of survival until as late as 36 weeks).

\section{Politicians' perspectives}

Unfortunately, some, including many politicians, redefine "late abortion" to apply from 20 weeks' gestation, although no significant event occurs at 20 weeks. Ironically, a baby born at 20 weeks would not be treated; but termination may be denied.

Women confronting these difficult decisions face both obstacles and public condemnation. Former Health Minister Tony Abbott has attributed Australia's high abortion rate to women whose lives are under control but who view childbirth as a "terrible inconvenience". ${ }^{17}$ Liberal moderate Christopher Pyne argued that terminations beyond 12 weeks were dubious, while they should not be performed at all after 21 weeks. ${ }^{18}$ Pyne supported federal prohibitions on second trimester abortions in the territories. ${ }^{19}$

In 2004, the then Deputy Prime Minister, John Anderson, lamented that there were too many abortions of "potential fellow Australians" each year. ${ }^{8}$ However, it is important to remember that women plan a family with a limited number of children. Abortion in the circumstance of fetal abnormality does not deny the country any "potential fellow Australians", as these women typically go on to have healthy children. Indeed, some women who have a disabled child choose to stop having children or have fewer children than they would otherwise have had. So, paradoxically, limiting late abortion may be reducing the number of new fellow Australians.

Many politicians claim that abortion laws are working well, including both Victorian ex-Premier Steve Bracks ${ }^{20}$ and opposition leader Ted Baillieu. ${ }^{21}$ This is clearly wrong.

\section{Conscientious objection}

One of us (JS) has argued at length that a doctor's conscience should not be allowed to interfere with medical care, and that the state must ensure that its public hospitals provide a reasonable 
service of medical interventions, which are beneficial to and desired by the patient, cost-effective and legal. ${ }^{22}$ If some individuals or institutions have moral objections to beneficial, desired, legal and just medical interventions, then those objections cannot compromise patient care. However, that is what is happening now.

\section{Conclusion}

Current abortion laws have serious adverse consequences. Women are being denied both timely prenatal testing and abortion for fetal abnormality. Women are less likely to choose to have a child, or more children, if they are not confident that access is available to both appropriate prenatal testing and abortion if a major abnormality is found. Governments wishing to encourage women to have children must take away barriers; they must clarify uncertain abortion laws. The best solution is the ACT model - to have no abortion laws within the Crimes Act.

Current practice is unfair and discriminatory. Access to prenatal testing and termination of pregnancy depends not on maternal or fetal considerations, but on where a woman happens to receive care, her personal resources, and the values and attitudes of the doctor, institution or ethics committee into whose hands she happens to fall. Women may be denied care to which they are legally entitled. There are inconsistent approaches to fetal moral status in obstetrics and paediatrics, with preterm infants being allowed to die but abortions being forbidden at the same gestation. This is indefensible.

Women wanting to have a baby deserve better. We need a more consistent approach to early human life, and we should move on from the current fear and uncertainty. We have the means to give many couples planning a family the opportunity to have healthy children, and less chance of children living short lives filled with suffering.

We have not attempted here to settle the ethics of abortion or late abortion. We have argued elsewhere that late abortion should be permitted. ${ }^{1,23}$ Doctors and ethics committees should explicitly present their values and moral arguments to their patients. ${ }^{24,25}$ Here, we have been concerned with the need to clarify what pregnant women are lawfully entitled to. At the end of ethical dialogue, if a woman requests an abortion, and she is legally entitled to it, she should receive it. If it is unlawful, it should not be offered. Current legal uncertainty results in care that compromises women and their families, and is discriminatory and inconsistent.

Some express the fear that clarification of the law may result in more restrictive laws. When $80 \%$ of Australians agree with a woman's right to choose an abortion, ${ }^{26}$ and this proportion is likely to be even higher when there is a major fetal abnormality, this seems unlikely.

\section{Acknowledgement}

We wish to acknowledge the obstetricians who kindly took the time to complete the survey.

\section{Competing interests}

None identified.

\section{Author details}

Lachlan J de Crespigny, MD, BS, FRANZCOG, Principal Fellow, ${ }^{1}$ and Honorary Fellow ${ }^{2}$

Julian Savulescu, MB BS, BMedSci, PhD, Uehiro Chair in Practical Ethics and Director ${ }^{3}$
1 Department of Obstetrics and Gynaecology, University of Melbourne, Melbourne, VIC.

2 Murdoch Childrens Research Institute, Melbourne, VIC.

3 Oxford Uehiro Centre for Practical Ethics, University of Oxford,

Oxford, UK.

Correspondence: lachlandec@yahoo.com.au

\section{References}

1 de Crespigny LJ, Savulescu J. Abortion: time to clarify Australia's confusing laws. Med J Aust 2004; 181: 201-203.

2 Victorian Law Reform Commission. The law of abortion. Information paper. Melbourne: VLRC, 2007. http://www.lawreform.vic.gov.au/ CA256902000FE154/Lookup/Abortion/\$file/final_web_version_info_ paper.pdf (accessed Nov 2007).

$3 R \vee$ Davidson [1969] VR 667 (the Menhennitt ruling).

4 Yusuf F, Siedlecky S. Legal abortion in South Australia: a review of the first 30 years. Aust N Z J Obstet Gynaecol 2002; 42: 15-21.

5 Modell B, Ward RH, Fairweather DV. Effect of introducing antenatal diagnosis on reproductive behaviour of families at risk for thalassaemia major. Br Med J 1980; 280: 1347-1350.

6 Harper PS, Walker DA, Tyler A, et al. Huntington's chorea. The basis for long-term prevention. Lancet 1979; 2: 346-349.

7 Harper PS, Tyler A, Smith S, et al. Decline in the predicted incidence of Huntington's chorea associated with systematic genetic counselling and family support. Lancet 1981; 2: 411-413.

8 Papadakis M. Hospital too scared to act. III fetus aborted at six months. Sunday Herald Sun (Melbourne) 2005; 13 Feb: 9.

9 Gerber P. Late-term abortion: what can be learned from Royal Women's Hospital v Medical Practitioners Board of Victoria? Med J Aust 2007; 186: 359-362.

10 The Consultative Council on Obstetric and Paediatric Mortality and Morbidity. Annual report for the year 2005, incorporating the 44th survey of perinatal deaths in Victoria. Melbourne: CCOPMM, 2007. http:// www.health.vic.gov.au/perinatal/downloads/ccopmm_annrep05.pdf (accessed Jun 2007).

11 Australian Medical Association. Australia needs consistent uniform national abortion laws to protect women and doctors [media release]. 15 Aug 2005. http://www.ama.com.au/web.nsf/doc/WEEN-6FA4DU (accessed Jun 2007).

12 Bell R. The 2003 RANZCOG Workforce Survey. O\&G 2003; 5 (3): 174-178.

13 Papadakis M. Woman denied legal abortion. Politics takes choice away. Sunday Herald Sun (Melbourne) 2005; 6 Feb: 10.

14 Curlin FA, Lawrence RE, Chin MH, Lantos JD. Religion, conscience, and controversial clinical practices. N Engl J Med 2007; 356: 593-600.

15 Lui K, Bajuk B, Foster K, et al. Perinatal care at the borderlines of viability: a consensus statement based on a NSW and ACT consensus workshop. Med J Aust 2006; 185: 495-500.

16 Nuffield Council on Bioethics. Critical care decisions in fetal and neonatal medicine: ethical issues. London: Nuffield Council on Bioethics, 2006. http://www.nuffieldbioethics.org/fileLibrary/pdf/CCD_web_version_8_ November.pdf (accessed Jun 2007).

17 Harvey M, Packham B. Babies inconvenient - Abbott. Herald Sun (Melbourne) 2007; Jan 6.

18 Symons E. New fight for the unborn. The Australian 2004; Nov 2: 13

19 Shanahan D. Let's have debate on abortion: Anderson. The Australian 2004; Nov 2: 2.

20 Tomazin F. Bracks wants status quo on state abortion stance. The Age (Melbourne) 2006; Sep 6.

21 Whinnett E. Baillieu declares war on the pokies. Herald Sun (Melbourne) 2006; May 13: 2.

22 Savulescu J. The proper place of values in the delivery of medicine. Am J Bioeth. Forthcoming.

23 Savulescu J. Is current practice around late termination of pregnancy eugenic and discriminatory? Maternal interests and abortion. J Med Ethics 2001; 27: 165-171.

24 Savulescu J. Rational non-interventional paternalism: why doctors ought to make judgments of what is best for their patients. J Med Ethics 1995; 21: $327-331$

25 Savulescu J. Liberal rationalism and medical decision-making. Bioethics 1997; 11: 115-129.

26 Betts K. Attitudes to abortion in Australia: 1972 to 2003. People Place 2004; 12 (4): 22-28.

(Received 19 Jul 2007, accepted 18 Nov 2007) 